Journal of Engineering and Applied Sciences 14 (16): 5789-5793, 2019

ISSN: 1816-949X

(C) Medwell Journals, 2019

\title{
Dielectric Characterization of Cedrus atlantica Wood at Low Frequencies
}

\author{
${ }^{1}$ A. Hakam, ${ }^{1} \mathrm{M}$. El Kortbi, ${ }^{1} \mathrm{M}$. Guelzim, ${ }^{2} \mathrm{~K}$. Iaych and ${ }^{1} \mathrm{M}$. Rahouti \\ ${ }^{1}$ Wood Science Laboratory, Faculty of Science, Mohammed V University in Rabat, \\ P.O. Box 1014, Rabat, Morocco \\ ${ }^{2}$ Academie des Arts Traditionnels, Fondation de la Mosquee Hassan II de Casablanca, \\ Casablanca, Morocco
}

\begin{abstract}
The Atlas Cedar Wood (ACW), Cedrus atlantica is a resinous species of Pinaceae originated from North Africa and well known for its noble timber and his economic importance. The characterization of (ACW) with a low frequency electrical field has not yet been studied. It may provide a valuable basis for determining defects in this wood non destructively and may help to understand wood-water interactions and hygroscopic characteristics of wood. The goal of this preliminary study was to examine the feasibility of this characterization and to study the effect of the frequency, wood anisotropy and thickness on the dielectric properties of (ACW). The dielectric constant $\left(\varepsilon^{\prime}\right)$ and dielectric loss factor $\left(\varepsilon^{\prime \prime}\right)$ were measured for heartwood specimens using frequencies between $10 \mathrm{~Hz}$ and $1 \mathrm{MHz}$ at $12 \%$ moisture content and room temperature $\left(20 \pm 2^{\circ} \mathrm{C}\right)$. The results obtained indicated a direct relationship between dielectric constants and thickness. The dielectric constant $\left(\varepsilon^{\prime}\right)$ and the dielectric loss factor $\left(\varepsilon^{\prime \prime}\right)$ showed an important increase with the increase of the thickness, especially at low frequencies.
\end{abstract}

Key words: Cedrus atlantica, atlas cedar wood, anisotropy, dielectric constant, dielectric loss factor, hygroscopic

\section{INTRODUCTION}

The cedar stands cover an area of 130.000 ha and occupy a privileged place in the Moroccan forest landscape. History of Morocco is based on very reach Islamic kingdoms, characterized by large dominations going from Maghreb up to South Spain. They largely utilized wood, especially the (AWC) to produce timber structures for buildings, decorations, furniture, high level joinery, music instruments and simple tools.

On the other hand, dielectric method is one of the potential methods for non-destructive analysis for assessment of wood anisotropy ( $\mathrm{Lin}, 1967$; Norimoto and Yamada, 1971; Norimoto et al., 1971, 1978) moisture content (Tiitta et al., 1999; Jinzhen and Guangjie, 2000, 2001), decay (Tiitta et al., 2003; Tiitta, 2006; Hakam et al., 2017 a), density and wood quality assessment (Tiitta et al., 2009). It measures the dielectric properties of a medium as a function of frequencies (Kremer and Schonhals, 2003). A significant relation between density and electrical properties, within a group of heartwood specimens had been reported (Skaar, 1948; Rafalski, 1966; Lin, 2007; Vermaas, 1973). Vermaas concluded that the dielectric constant $\left(\varepsilon^{\prime}\right)$ for all directions increased with the increase of density and moisture content and decreased with the increased frequency. It is also reported that the detection of knots, drying defects and spiral grain are possible by measuring dielectric properties of wood (Martin et al., 1987). Some electrical properties of Moroccan wood species and cork leaves were reported(El Alami et al., 2012; Hakam and El Imame, 2017; Hakam et al., 2017a, b; Hakam et al., 2012 and Lazrak et al., 2018). The purpose of the present study was to examine the feasibility of the low frequency dielectric method and to study the effect of the frequency, wood anisotropy and thickness on the dielectric constant $\left(\varepsilon^{\prime}\right)$ and the loss factor $\left(\varepsilon^{\prime \prime}\right)$ of ACW heartwood.

\section{MATERIALS AND METHODS}

The wood specimens (Cedrus atlantica Manetti, heartwood) were obtained from Forest Research Center, Rabat (Morocco). Threes of 75 year's-old ACW was selected and felled from the mature stands in the Azrou region in the Meknes Province ( $33^{\circ} 26^{\prime} \mathrm{N}, 5^{\circ} 13^{\prime} \mathrm{W}, 1250 \mathrm{~m}$ asl.). A sub-sample of three trees was selected and 6 samples of each tree at average height of $1.3 \mathrm{~m}$ were cut for study. The specimens were cut from the plate into

Corresponding Author: A. Hakam, Wood Science Laboratory, Faculty of Science, Mohammed V University, P.O. Box 1014, Rabat, Morocco 
square pieces of $20 \mathrm{~mm}$ and of $2-4 \mathrm{~mm}$ in thickness in longitudinal, radial and tangential direction to the growth ring and gently smoothed by sanding (Fig. 1). All specimens were free of cracks, discoloration, biological attack, insect holes and other defects. Before the test, all specimens were put into a climatic chamber $\left(20 \pm 2^{\circ} \mathrm{C}\right.$ and $65 \pm 5 \%$ relative humidity) in order to reach the wood moisture equilibrium content of $12 \%$. In study heartwood samples was analyzed under normal laboratory conditions.

Density measurements: Before the impedance measurements the samples were weighed and the dimensions were measured. After the impedance measurements, the specimens were dried at $103 \pm 3^{\circ} \mathrm{C}$ for 24 $\mathrm{h}$ and weighed. The dimensions, moisture content and densities were measured with $0.1 \mathrm{mg}$ accuracy in weight and $0.02 \mathrm{~mm}$ for dimensions. The moisture content was calculated with:

$$
\mathrm{MC}=\frac{100 \times\left(\mathrm{M}_{\mathrm{h}}-\mathrm{M}_{0}\right)}{\mathrm{M}_{0}}
$$

Where:

$\mathrm{M}_{\mathrm{h}}=$ Air-dry mass before the impedance measurements $\mathrm{M}_{0}=$ The oven-dry mass after drying at $103 \pm 3^{\circ} \mathrm{C}$ for $24 \mathrm{~h}$

Apparent (air-dry) density: $\left(\mathrm{D}_{\mathrm{h}}\right)$ was determined as $\mathrm{M}_{\mathrm{h}} / \mathrm{V}_{\mathrm{h}}$ where, $\mathrm{M}_{\mathrm{h}}$ and $\mathrm{V}_{\mathrm{h}}$ are air-dry mass and volume before drying. Oven-dry (anhydrous) Density $\left(\mathrm{D}_{0}\right)$ was determined as $M_{0} / V_{0}$ where, $M_{0}$ and $V_{0}$ are mass and volume after drying.

Dielectric measurements: The dielectric constant $\left(\boldsymbol{\varepsilon}^{\prime}\right)$ and dielectric loss factor $\left(\varepsilon^{\prime \prime}\right)$ of the heartwood ACW specimens were measured in the atmospheric conditions in the frequency range from $10 \mathrm{~Hz}$ to $1 \mathrm{MHz}$, at which the effect of the electrode type was negligible. These measurements were carried out using an LCZ meter HP 4192A and a pair of plates and circular metallic electrodes with a diameter of $20 \mathrm{~mm}$ for three anisotropic directions:

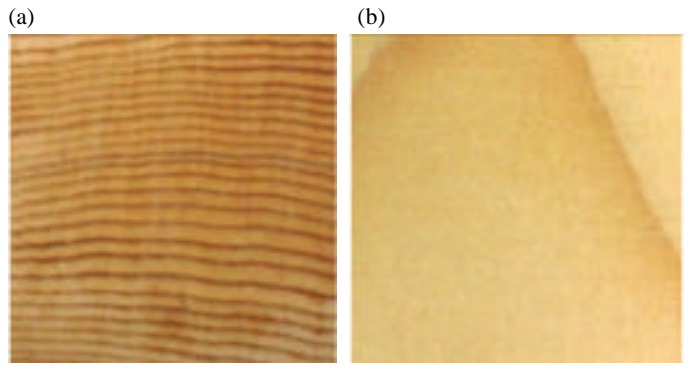

Fig. 1: Contact surfaces of the samples for the two planes: a) Transverse ( $\mathrm{Tr}$ ) and b) Tangential ( $\mathrm{Tg}$ ) longitudinal, radial and tangential at $12 \%$ moisture content of specimens and at a room temperature $\left(20 \pm 2^{\circ} \mathrm{C}\right)$. No gel was used between the electrodes to avoid the absorption of the gel into the specimens.

\section{RESULTS AND DISCUSSION}

Density: The densities of ACW specimens are given in Table 1 . The values obtained are in the medium range for commercially used wood.

Electrical measurements: The curves representing the effect of the anisotropy and the thickness of the wood on the dielectric constant $\left(\boldsymbol{\varepsilon}^{\prime}\right)$ and the loss factor $\left(\boldsymbol{\varepsilon}^{\prime \prime}\right)$ of the 18 cedar wood specimens were similar.

Effect of wood anisotropy on dielectric properties: The dielectric constant $\left(\boldsymbol{\varepsilon}^{\prime}\right)$ of ACW for $2 \mathrm{~mm}$ thick specimens with $12 \% \mathrm{MC}$ at $20 \pm 2{ }^{\circ} \mathrm{C}$ as function of frequencies from $10 \mathrm{~Hz}$ to $1 \mathrm{MHz}$ in the Longitudinal (L) Radial (R) and Tangential ( $\mathrm{T}$ ) directions is shown in Fig. 2.

The dielectric constant of ACW decreases with the increase of the frequency of the applied electrical field. At low frequencies, complete orientation of the dipoles is possible leading to higher dielectric constant. However, at high frequencies the molecular vibrations are higher, the complete orientation of dipoles does not take place and then the dielectric constant decreases as the frequency increases. The value of $\varepsilon^{\prime}$ at high frequency decreased in the following order: $\mathrm{L}$ direction $>\mathrm{R}$ direction and $\mathrm{T}$ direction where by the dielectric constant is larger for the polarization parallel to the grain than across the grain and the radial values were similar to the tangential

\begin{tabular}{lllll}
\multicolumn{6}{l}{ Table 1: Densities of ACW } \\
\hline Density & Ave. & Max & Min & CV (\%) \\
\hline $\mathrm{D}_{\mathrm{h}}$ & 0.595 & 0.695 & 0.491 & 7.899 \\
$\mathrm{D}_{0}$ & 0.460 & 0.530 & 0.386 & 7.391 \\
\hline
\end{tabular}

$\mathrm{D}_{\mathrm{h}}$ is apparent (air-dry) density and $\mathrm{D}_{0}$ is oven-dry (anhy drous) density

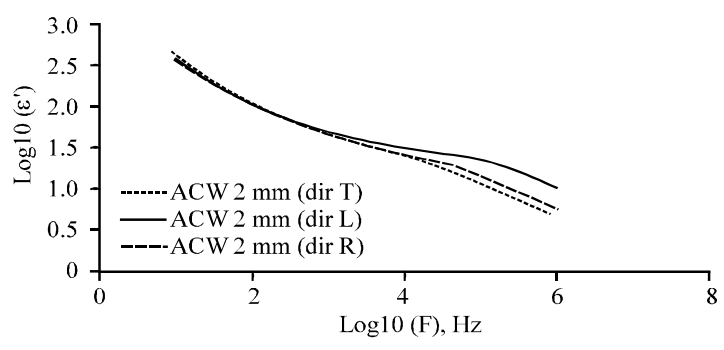

Fig. 2: Logarithmic dielectric constant $\left(\boldsymbol{\varepsilon}^{\prime}\right)$ of ACW as a function of logarithmic frequency in the three principal directions to the grain of $2 \mathrm{~mm}$ thick specimen 
values. This anisotropy was considered to be due to the difference in the arrangement of lumens (air ducts) and the cell walls in both directions. The hydroxyl groups of the cellulose should have more free rotation longitudinally than in the radial and tangential directions (Lin, 1967; Norimoto et al., 1978). The effects of anisotropy on the loss factor $\left(\varepsilon^{\prime \prime}\right)$ and $\left(\varepsilon^{\prime \prime} / \varepsilon^{\prime}\right)$ of ACW of $2 \mathrm{~mm}$ thick specimens with $12 \% \mathrm{MC}$ at $20 \pm 2^{\circ} \mathrm{C}$ and at frequencies from $10 \mathrm{~Hz}$ to $1 \mathrm{MHz}$ in the Longitudinal (L), Radial (R) and Tangential $(\mathrm{T})$ directions are graphically presented in Fig. 3 and 4, respectively.

The dielectric loss factors $\left(\varepsilon^{\prime \prime}\right)$ of ACW decreased also as frequencies increased in all grain directions (Fig. 3). This result indicated that the relative dielectric constant was higher for the polarization parallel to the grain than across the grain. This behavior was expected from the fact that the hydroxyl groups of the cellulose should have more freedom of rotation in the longitudinal direction than in radial and tangential direction result on good agreement with (Norimoto et al., 1978; Lin, 1967).

Effect of wood thickness on dielectric properties: Figure 5 dielectric constants $\left(\varepsilon^{\prime}\right)$ of $\mathrm{ACW}$ in longitudinal

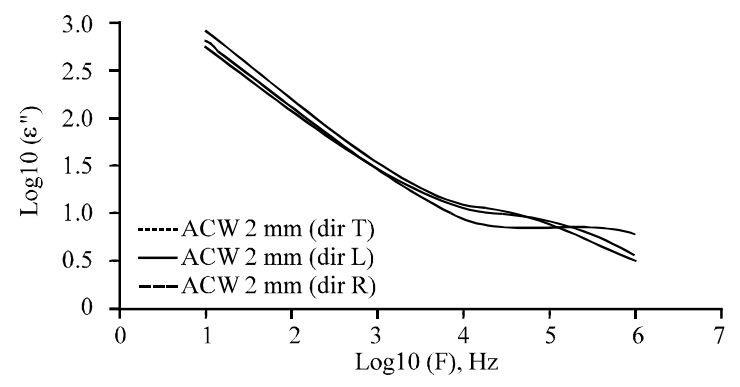

Fig. 3: Logarithmic dielectric constant ( $\left(\varepsilon^{\prime \prime}\right)$ of $\mathrm{ACW}$ as a function of logarithmic frequency in the three principal directions to the grain of $2 \mathrm{~mm}$ thick specimen direction are plotted as a function of frequency for specimen thicknesses ( 2 and $4 \mathrm{~mm}$ ). Thickness had an effect on the electrical properties over the whole frequency range. Dielectric loss factor $\left(\varepsilon^{\prime \prime}\right)$ of $\mathrm{ACW}$ in longitudinal direction as a function of frequency for 2 specimen thicknesses ( 2 and $4 \mathrm{~mm}$ ) is shown in Fig. 6.

A dielectric process could be clearly observed in the frequency region centered around $10^{6} \mathrm{~Hz}$ (Fig. 4 and 6) (In this frequency region only the half of the peak of dielectric process appear). Norimoto and Yamada (1970) suggested that this relaxation process is caused by the reorientation of $\mathrm{CH}_{2} \mathrm{OH}$ group in the amorphous region of wood cell wall. Cao and Zhao observed the similar behavior at studying the dielectric properties of wood in moisture equilibrium state. The effect of thickness is clearly observed in Fig. 5 and 6 for thicknesses of 2 and 4 $\mathrm{mm}$. The dielectric constant and the dielectric loss factor showed an important increase with the increase of the thickness, especially at high frequencies. The value of $\varepsilon^{\prime \prime}$ of thicker $(4 \mathrm{~mm}) \mathrm{ACW}$ was higher than that of $2 \mathrm{~mm}$ $\mathrm{ACW}$. Both dielectric constants and dielectric loss factors (Fig. 5 and 6) increased with the increase in thickness at frequencies studied, at lower frequencies the effect was sometimes masked by noise. It is obvious that the effect of the specimen's thickness on dielectric constant $\left(\varepsilon^{\prime}\right)$ or dielectric loss factor $\left(\varepsilon^{\prime \prime}\right)$ was small compared to the effects of moisture content and frequency. The increase in the dielectric constant with thickness can be explained by the fact that increasing thickness leads to an increase in the number of polar groups inside the sample which leads to an increase in orientation of the polarization. As a result of such effect the dielectric constant increases with thickness at all frequencies. The dielectric loss factors $\left(\varepsilon^{\prime \prime}\right)$ obtained were of a minimal value (Fig. 6). These minimal loss factors

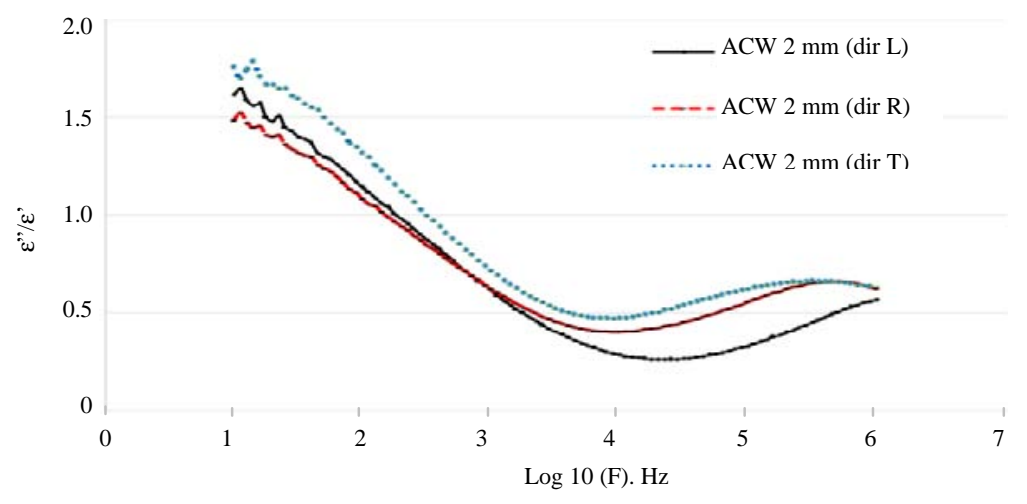

Fig. 4: The $\varepsilon^{\prime \prime} / \varepsilon^{\prime}$ of ACW as a function of logarithmic frequency in the three principal directions to the grain of $2 \mathrm{~mm}$ thick specimen 


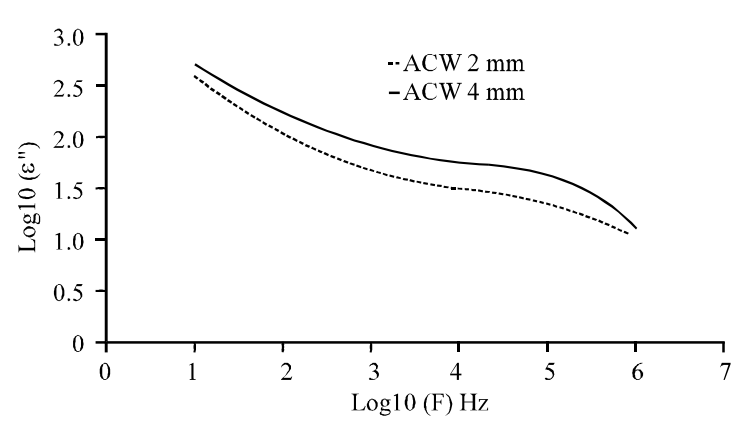

Fig. 5: Logarithmic dielectric constant $\left(\varepsilon^{\prime}\right)$ of ACW in longitudinal direction as a function of logarithmic frequency for two specimen thicknesses (2 and 4 $\mathrm{mm}$ )

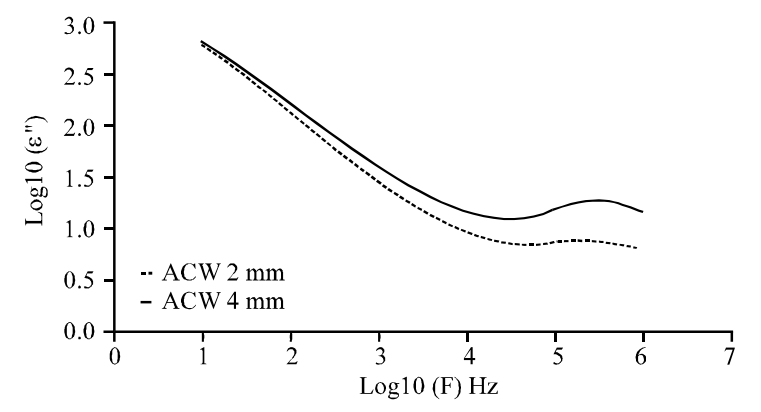

Fig. 6: Logarithmic dielectric loss factor $\left(\varepsilon^{\prime \prime}\right)$ of $\mathrm{ACW}$ in longitudinal direction as a function of logarithmic frequency for specimen thicknesses ( 2 and $4 \mathrm{~mm}$ )

shifted towards lower frequencies with increases in thickness. The ration $\left(\varepsilon^{\prime \prime} / \varepsilon^{\prime}\right)$ obtained were of a minimal value (Fig. 4). These minimal shifted towards lower frequencies in the following order: $\mathrm{L}$ direction $>\mathrm{R}$ direction and $\mathrm{T}$ direction. A minimum value for the loss factor in the same frequency region $\left(30\right.$ to $10^{6} \mathrm{~Hz}$ ) was also reported by Norimoto and Yamada (1970) for kusunoki wood.

\section{CONCLUSION}

The aim of this study was to determine the dielectric characteristics of Atlas Cedar Wood (ACW) (Cedrus atlantica Manetti) at low frequency. The dielectric constant $\left(\varepsilon^{\prime}\right)$ and dielectric loss factor $\left(\varepsilon^{\prime \prime}\right)$ of $\mathrm{ACW}$ specimens were measured in atmospheric conditions at $20 \pm 2^{\circ} \mathrm{C}$ and $10 \mathrm{~Hz}$ to $1 \mathrm{MHz}$ frequency range in which the effect of the electrode was negligible. The effect of wood anisotropy and thickness on the dielectric constant $\left(\varepsilon^{\prime}\right)$ and the loss factor $\left(\varepsilon^{\prime \prime}\right)$ of ACW heartwood by means of dielectric method at low frequencies were examined. The effect of wood anisotropy was investigated in longitudinal, radial and tangential direction to the growth ring. The specimen thickness impact on the electrical properties within ACW heartwood specimens had been reported. The observed changes in dielectric properties of ACW due to thickness indicated that at a constant temperature and moisture content, both the dielectric constant $\left(\varepsilon^{\prime}\right)$ and the loss factor $\left(\varepsilon^{\prime \prime}\right)$ increase with the increase of the thickness over the whole frequency range. The increase in thickness leads to increase in the amount of bound water and therefore, an increase in the value of the dielectric constant. The dielectric loss factor exhibited minimum values which were shifted to the lower frequency with decreased thickness.

\section{REFERENCES}

El Alami, S., A. Hakam, M. Ziani, N.A. Chantoufi and Z. Hamoutahra et al., 2012. Dielectric behaviour of Aleppo pine, Holm oak and Thuja burl woods in microwaves range $(0.13$ TO $20 \mathrm{GHz})$. Phys. Chem. News, 64: 53-58.

Hakam, A. and N. El Imame, 2017. Frequency response modelling of maritime pine (Pinus pinaster L.) wood at low frequencies. J. Mater. Environ. Sci., 8: 4362-4366.

Hakam, A., M.M. Takam, M. Chokairi, N.A. Chantoufi and Z. Hamoutahra et al., 2012. Effect of bark stripping on the electrical impedance of Quercus suber leaves. Maderas. Cienc. Tecnol., 14: 195-208.

Hakam, A., N. El Imame, M. Ziani, A. Famiri and M. Hachmi et al., 2017b. Electrical study of maritime pine wood in relation to blue stain. Intl. J. Appl. Eng. Res., 12: 11050-11054.

Hakam, A., N.A. Chantoufi, N. El Imame, M. Guelzim and M. Ziani et al., 2017a. Dielectric properties of atlas cedar wood at its early stage of decay. Intl. J. Pharmacogn. Phytochem. Res., 9: 444-448.

Jinzhen, C. and Z. Guangjie, 2000. Dielectric relaxation based on adsorbed water in wood cell wall under non-equilibrium state. 1. Holzforschung, 54: 321-326.

Jinzhen, C. and Z. Guangjie, 2001. Dielectric relaxation based on adsorbed water in wood cell wall under non-equilibrium state 2. Holzforschung, 55: 87-92.

Kremer K. and A. Schonhals, 2003. Broadband Dielectric Spectroscopy. Springer, Berlin, Germany, ISBN: 978-3-642-62809-2, Pages: 729.

Lazrak, C., A. Hakam, M. Hammi, A. Famiri and M. Ziani, 2018. Examination of interfacial compatibility within WPC panels using electrical impedance spectroscopy. J. Eng. Appl. Sci., 13: 2786-2790.

Lin, R.T., 1967. Review of the electrical properties of wood and cellulose. Forest Prod. J., 17: 54-66. 
Lin, R.T., 2007. Wood as an orthotropic dielectric material. Wood Fiber Sci., 5: 226-236.

Martin, P., R. Collet, P. Barthelemy and G. Roussy, 1987. Evaluation of wood characteristics: Internal scanning of the material by microwaves. Wood Sci. Technol., 21: 361-371.

Norimoto, M. and T. Yamada, 1970. The dielectric properties of wood IV: On dielectric dispersions of oven-dried wood. Wood Res., 50: 36-49.

Norimoto, M. and T. Yamada, 1971. The dielectric properties of wood $\mathrm{v}$, on the dielectric anisotropy of wood. Wood Res. Kyoto, 51: 12-32.

Norimoto, M., S. Hayashi and T. Yamada, 1971. Anisotropy of dielectric constant in coniferous wood. Holzforschung, 51: 12-32.

Norimoto, M., S. Hayashi and T. Yamada, 1978. Anisotropy of dielectric constant in coniferous wood. Holzforschung Intl. J. Bio. Chem. Phys. Technol. Wood, 32: 167-172.

Rafalski, J., 1966. [About the dielectric properties differently densified red-beech wood (In Arabic)]. Holztechnologie, 7: 118-122.
Skaar, C., 1948. The dielectric properties of wood at several radio frequencies. Master Thesis, Syracuse University, Syracuse, New York, USA.

Tiitta, M., 2006. On destructive methods for characterization of wood material. Ph.D Thesis, Department of Physics, University of Kuopio, Finland.

Tiitta, M., L. Tomppo, H. Jarnstrom, M. Loija and T. Laakso et al., 2009. Spectral and chemical analyses of mould development on Scots pine heartwood. Eur. J. Wood Prod., 67: 151-158.

Tiitta, M., P. Kainulainen, A.M. Harju, M. Venalainen and A.M. Manninen et al., 2003. Comparing the effect of chemical and physical properties on complex electrical impedance of Scots pine wood. Holzforschung, 57: 433-439.

Tiitta, M., T. Savolainen, H. Olkkonen and T. Kanko, 1999. Wood moisture gradient analysis by electrical impedance spectroscopy. Holzforschung, 53: 68-76.

Vermaas, H.F., 1973. Regression equations for determining the dielectric properties of wood. Holzforschung Intl. J. Bio. Chem. Phys. Technol. Wood, 27: 132-136. 